\title{
Expanding on Parkinson's Law
}

SiR, - Parkinson summarised his large experience of administration in the law that Work Expands So As To Fill The Time Available For Its Completion (C.N. Parkinson, Parkinson's Law, 1958). A corollary of this law, that the proportion of administrators within a public organization tends to increase with the size of that organization, has been confirmed by empirical observation (R. Moss, Nature, 273, page 184, 1978). Schumacher in Small is Beautiful (1974), challenged conventional wisdom by showing that large, centralized organizations are often less efficient than small ones, and Moss made observations on the staffing structure of the Natural Environment

Research Council (NERC) which showed that component bodies of NERC in which the administration was dispersed amongst many addresses have fewer administrators and other support staff than other, more centralized bodies of comparable size. Further, J. Flux's detailed study of the Ecology Division of the New Zealand Department of Scientific and Industrial Research (in Focus on Social Responsibility in Science, 1979), showed that the production of scientific papers per man decreased as the organization increased in size.

These scientific observations have not been

followed by a reorganization in the administration of scientific research. Colleagues have suggested that this is partly because the original empirical observations were not accompanied by a theoretical model. Such a model is therefore presented.

Consider the situation in which we have a number $W(W=4$ in the example of the figure) of individuals or groups of individuals doing a certain amount of work such as making scientific discoveries or collecting tax. The simplest possible situation is that each individual worker gets on with his job, pausing occasionally to speak with colleagues, answer letters and arrange for the office windows to be cleaned. As W increases, such primitive liaison techniques may become less effective and an administrator may be appointed.

In the model, the administrative workload of an individual is a function of the number of people with whom he communicates. This is the number of lines of communication l, as may be seen in the figure and, for brevity, is subsequently referred to as 'workload'. In stage one of the model each speaks with each of his colleagues and also with the outside world

$$
1_{w i}=W
$$

where $1_{\text {w }}$ is the workload of worker $i$.

In stage two of the model, when the administrator is newly appointed, each worker continued to speak with other workers, but also communicates with the administrator. Of course a 'worker' in this model could as easily be a constituent organization within an 'umbrella' organization such as the Agricultural Research Council (ARC), the Medical Research Council (MRC) or NERC. In stage two

$$
\begin{array}{ll}
\text { and, as before } & \mathrm{l}_{\mathrm{ai}}=\mathrm{W}+1 \\
& \mathrm{l}_{\mathrm{wi}}=\mathrm{W}
\end{array}
$$

where $l_{a j}$ is the workload of administrator $i$ (of course the suffix is redundant at this stage, but it becomes useful later)

When the excitement of reorganization has settled into the humdrum of routine, the administrator has an idea which many readers will recognise. "It is grossly inefficient for all of you (W) to be wasting time liaising both with each other and with me $\left(a_{1}\right)$. Let us reorganize our lines of communication so that you all communicate through me". This is

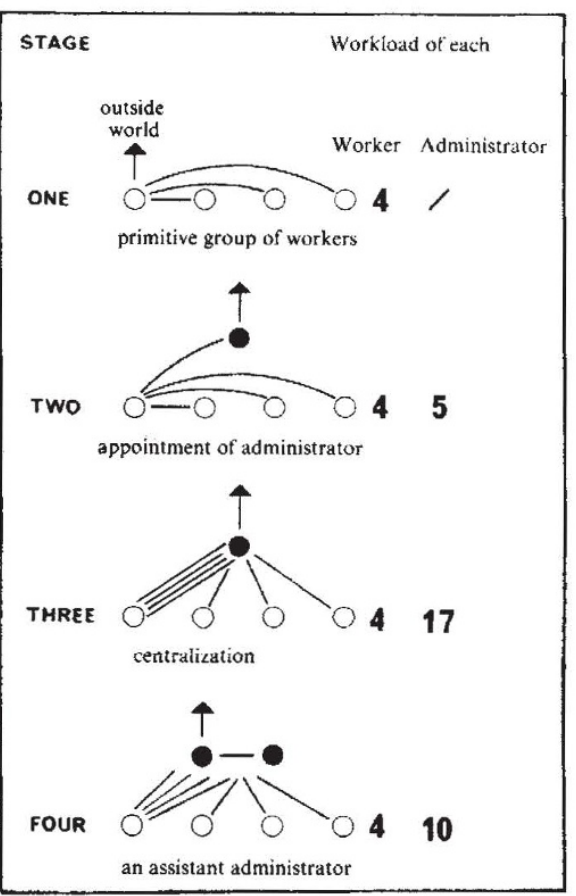

Figure, Illustrating the number of lines of communication (administrative workload) between members of an organization containing four workers, as it passes through the four stages of Parkinson's Progression.

Note. For clarity, lines of communication for one worker only are shown - lines of communication for the others follow an identical pattern.

stage three in the figure. "That will be much more efficient". Efficiency, of course, is only one objective of this course of action. Lust for power is an important motivation and the concept of 'accountability' is often pressed into use at this stage.

In stage three the workload of each worker remains the same, although cooperation amongst them is slowed down by the length of time that their messages lie on the

administrator's desk. But the workload of the hard-pressed administrator now rises sharply as he grapples with all the matters that had previously been the subject of direct communication between workers. As well as communicating directly with $\mathrm{W}$ and the outside world, he now passes minutes to and from all the $\mathrm{W}$.

$$
\begin{array}{ll}
\text { and, as before } & 1_{\mathrm{ai}}=\mathrm{W}^{2}+1 \\
& \mathrm{l}_{\mathrm{wj}}=\mathrm{W}
\end{array}
$$

This situation is intolerable: in our example it can be seen that the administrator's workload has increased by more than three times, without any increase in the number of workers. This is the effect of centralization. In desperation our administrator applies for assistance. This is stage four where efficient co-operation amongst administrators gives

and, as before

$$
\mathrm{lai}_{\mathrm{i}}=\frac{\mathrm{W}^{2}}{\mathrm{~A}}+\mathrm{A}
$$

$$
1_{w i}=W^{2}+A
$$

A being the number of administrators. Our exemplary administrator in the figure has thriftily indented for only one assistant and so the number of administrators has now doubled, but the workload of each is nonetheless double what it was in stage two. Both administrators are working very hard, as evidenced by the large number of minutes processed since stage four came into operation. More assistants may well be needed to cope with the increased workload.

Our two administrators may well assume that the more colleagues they have, the smaller will be their individual workload. This is true up to a point, the point being four administrators to four workers in our example Beyond that number, however, $1_{\mathrm{ai}}$ increases again as the administrators spend an increasing proportion of their time sending minutes to each other. In general, the minimum workload per administrator $\mathrm{l}_{\mathrm{ai}_{\min }}$ is attained when $\mathrm{A}=\mathrm{W}$, that is when the ${ }_{\text {min }}$ proportion of administrators in the organization is $50 \%$. This may well be the 'maximum ratio' referred to by Parkinson, beyond which the proportion of administrators is unlikely to increase. It is notable that the maximum percentage of nonscientific staff in any of the component bodies of NERC is exactly $50 \%$.

At this point, let us turn our attention to the next rank up in the hierarchy, the chief administrator $c$ who appointed our administrators in the first place and to whom they are responsible. His workload will increase as A increases. Initially, his workload will bear the same relation to $A$ as that of $A$ did to W. But, as A increases, he may decide that further centralization is called for in pursuit of increased efficiency ... with the inevitable consequence that stages three and four repeat themselves at this and possibly higher levels in the hierarchy.

Parkinson's Law has long been regarded as a joke by administrators who know that they work very hard. But what do they work hard at? The writer's experience is that questions such as this, pursued in the course of objective scientific analysis, are sometimes resented by administrators of scientific organizations. The model presented here shows simply and not unrealistically that the effects of centralization are to increase the amount of information that an administrator processes, whilst decreasing the proportion of workers in the organization. Had this model been available and accepted by those in authority some years ago, the reorganization of, for example, local government and the National Health Service, accompanied by decreased standards of service and increased administrative staffs, might not have occurred.

A problem with the model is the simplified assumption that all lines of communication are equivalent in the amount or work that they represent. A logical step next is to test the robustness of this approximation by making measurements of the amount of work per line of communication in the field, factory, office or laboratory.

The principles that the number of administrators tends to increase irrespective of the amount of external work done by an organization, due to Parkinson, and that increased centralization is accompanied by decreased effectiveness, pointed out by Schumacher ${ }^{2}$, were empirical and inductive observations made by wise and experienced men. I provide a deductive and quantitative basis for these classic observations, a step towards management by reason rather than intuition.

$$
\text { Yours faithfully, }
$$

Station House, Crathes,

ROBERT MOSS

by Banchory Kincardineshire, Scotland. 